\title{
HUMANIZAR A ASSISTÊNCIA NAS SITUAÇÕES DE ABORTAMENTO NO SUS: O DESAFIO PERMANECE
}

\section{HUMANIZING ASSISTANCE IN ABORTION SITUATIONS IN SUS: THE CHALLENGE REMAINS}

\author{
Maria Alice Ramos Ferreira Leal*, Marilda Castelar**
}

Autora para correspondência: Maria Alice Ramos Ferreira Leal - alicefleal@hotmail.com

*Psicóloga e Psicanalista no Hospital Geral Roberto Santos

**Doutora em Psicologia pela PUC-SP. Professora da Escola Bahiana de Medicina e Saúde Pública

\section{R E S U M O}

\begin{abstract}
Introdução: $O$ abortamento introduz uma gama de complexidades no campo da saúde, sendo necessário analisá-lo sob diferentes enfoques. Objetivo: Assim, a presente revisão de literatura traça um panorama de suas dimensões antropológica, histórica e política, com o objetivo de obter elementos para compreender as dificuldades que interferem na humanização da assistência. Método: Para tanto, realizou-se um levantamento bibliográfico em uma perspectiva sócio-histórica de autores com reconhecidos trabalhos sobre a temática, e de pesquisas publicadas nos últimos sete anos que avaliam e analisam a assistência prestada às mulheres adultas e adolescentes em situação de abortamento, nos serviços assistenciais no âmbito do Sistema Único de Saúde brasileiro. Neste artigo, os documentos oficiais do Ministério da Saúde sobre a Política Nacional de Humanização, bem como a Norma Técnica de Humanização ao Abortamento, foram tomados como textos norteadores para definição de uma prática assistencial humanizada. Conclusão: Os cenários de assistência obstétrica, descritos pelos pesquisadores, permitiram concluir que há ainda uma distância significativa entre o que está preconizado e a assistência que vem sendo prestada, tornando-se necessário desnaturalizar formas de assistência já cristalizadas para alcançar um novo paradigma de atenção à saúde nas situações de abortamento.
\end{abstract}

Palavras-chave: Abortamento. Políticas Públicas. SUS. Humanização. 
Introduction: The abortion introduces a range of complexities in the field of health, being necessary to analyze it from different approaches. Objective: Thus, this present review outlines a brief overview of its anthropological, historical and political dimensions, in order to obtain elements to understand the difficulties that interfere with the humanization of care. Method: Therefore, a literature review, in a socio-historical perspective of authors with recognized reports on the subject was conducted, as much as research published in the last seven years that evaluates and analyzes the care provided to adults and adolescent women in situations of abortion in health services under the Brazilian Public Universal Health Care System. In this article, the official documents of the Ministry of Health regarding the National Humanization Policy and the Technical Standard of humanization to abortion were taken as guiding texts for a definition of a humanized care practice. Conclusion: The obstetric care scenarios, described by the researchers concluded that there is still a significant gap between what is recommended and the assistance that has been provided, making it necessary to denature forms of assistance already crystallized to reach a new health care paradigm in situations of abortion.

Keywords: Abortion. Public Policies. SUS. Humanization. 


\section{INTRODUÇÃO}

O Ministério da Saúde (MS) tem criado políticas públicas, respaldadas em acordos internacionais e na legislação brasileira, com o objetivo de assegurar o cumprimento dos direitos humanos nas situações de abortamento. Entretanto, na prática, ainda são observadas dificuldades para efetivar uma assistência humanizada, na medida em que nessas situações vêm à tona questionamentos sobre legalidade, criminalização, moralidade e religiosidade, fatores que interferem no posicionamento e desempenho dos profissionais de saúde. Constata-se que os conceitos e os valores dos profissionais de saúde e dos gestores sobre o aborto ultrapassam os limites das simples convicções pessoais: são determinados historicamente pelos processos sociais e culturais, que se entrecruzam na formação profissional e incidem nas práticas em espaços institucionais'.

A seguir, o breve delineamento do abortamento em diferentes dimensões visa a fornecer elementos para a compreensão das questões que tensionam o plano relacional entre os profissionais e as usuárias do Sistema Único de Saúde (SUS), analisando aspectos que iluminam os obstáculos que emergem no campo assistencial.

\section{MÉTODO}

Realizou-se uma busca nas bases de dados do SciELO (Scientific Electronic Library Online), LILACS (Literatura Latino-americana e do Caribe em Ciências da Saúde) e em banco de teses, utilizandose os descritores "aborto induzido" e sinônimos, "humanização" e "adolescência". Foram consultados autores com reconhecidos trabalhos sobre o tema, tanto em livros como em artigos, sendo o que ano de publicação dos artigos foi o critério de sua inclusão, de modo que pudessem retratar o atual momento da assistência, em casos de abortamento no Brasil. Assim, foram excluídos artigos com mais de sete anos de publicação e os que estavam distantes da realidade da assistência terciária obstétrica em caso de aborto. Os textos do Ministério da Saúde sobre a humanização balizaram o percurso metodológico aqui traçado.

\section{O abortamento em sua dimensão antropológica,} histórica e política

Estudos antropológicos sobre $\bigcirc$ abortamento, empreendidos em meados do século $X^{2}$ nas sociedades ditas primitivas ou pré-industriais, permitiram constatar o provável caráter universal da prática do aborto voluntário ou, pelo menos, - reconhecimento dessa ocorrência. A pesquisa etnográfica constata que não há interlocutor, nas mais diferentes culturas, que ignore ou se espante com a possibilidade de retirar e eliminar fetos do corpo antes do nascimento, o que leva o sociólogo Luc Boltanski a deduzir que o abortamento provocado faz parte "[...] dos quadros fundamentais da existência humana em sociedade"3.

Métodos com a finalidade de provocar o aborto foram identificados em diferentes momentos da história. Estão presentes na Antiguidade greco-romana, nas sociedades ocidentais medievais e modernas, bem como no Oriente, a exemplo da China e do Japão. Recorre-se mais frequentemente a drogas abortivas, em geral fitoterápicas, como também aos meios mecânicos internos (introdução no corpo feminino de objetos pontiagudos) ou aos mecânicos externos, como pulos, golpes, cintos apertando o ventre, entre outros. Ademais, a etnologia registra igualmente meios mágicos, tais como, sentar-se em alguma árvore, comer determinado alimento, entre outras medidas ${ }^{3}$.

Algumas propriedades referentes ao abortamento voluntário são identificadas por Luc Boltanski ${ }^{3}$ : além de sua universalidade, encontra-se a sua reprovação geral - inclusive nas sociedades nas quais sua prática é frequente - e observam-se reações contrárias à simples menção da palavra aborto, que pode desencadear desde uma censura discreta até a mais violenta indignação, muitas vezes simulada, como que para satisfazer às supostas expectativas do pesquisador. Ao mesmo tempo, não se fala do abortamento de modo frontal; percebe-se 0 constrangimento e a tentativa de fazer crer que essa prática não diz respeito a quem fala, nem mesmo aos membros mais próximos do coletivo ao qual se pertence. Observa-se, contudo, que as reações são muito variadas de sociedade para sociedade, como também no interior de um mesmo agrupamento 
social. Situações em que a paternidade não pode ser confirmada ou características do feto - a exemplo de ser considerado filho de mau espírito (filho de um demônio) são, às vezes, apresentadas como circunstâncias atenuantes do abortamento, mas apenas de modo sutil, não se constituindo em uma argumentação segura, sustentada inequivocamente ${ }^{3}$.

Em que pese a fragilidade sobre argumentos que buscam atenuar tal prática, Luc Boltanski percebe que sua reprovação é acompanhada, não raro, de uma tolerância, mesmo por parte daqueles que se indignam à sua simples evocação. Essa tolerância se constitui, para o autor, como outra propriedade relevante do abortamento, que pode ser observada pelos poucos esforços, em geral, empregados para identificar e punir os responsáveis pelos abortamentos, tanto nas sociedades medievais quanto nas modernas, ou mesmo nas cristãs, que sempre censuraram e insistiram em sua proibição ${ }^{3}$.

O abortamento pôde assim permanecer velado, de certo modo inacessível, por pertencer quase que exclusivamente ao "mundo das mulheres". Diversos estudos ${ }^{2,3}$ revelam uma nítida distinção de gênero, na qual o mundo masculino é identificado como oficial, encontrando na polis o seu espaço privilegiado, em contraposição ao mundo das mulheres que se apresenta como oculto, "privado", oficioso, no qual se reserva à prática do abortamento o lugar mais encoberto e, com efeito, afastado da vida pública ${ }^{3}$.

Entretanto, a prática do abortamento só vai se tornar radicalmente clandestina nos países ocidentais em meados do século XIX até metade do século $X X$, intervalo no qual o aborto se torna ilegal e penalizado ${ }^{3}$. Pode-se inferir que essa forma mais explícita de censura ocorreu, muito provavelmente, como consequência do que Foucault designa como a "biopolítica" 4,5 , que emerge no século XVIII, momento em que $\circ$ Ocidente vai testemunhar uma importante transformação nos mecanismos de poder. $O$ antigo "poder soberano", que outorgava o direito de causar a morte ou deixar viver, vai sofrer um deslizamento para um poder que busca causar a vida, ordenar e gerir suas funções ${ }^{4,5}$.

Foucault, em sua obra A História da Sexualidade, no volume 1, A Vontade de Saber, destaca que, de um lado, as disciplinas do corpo, que o adestram, ampliam as aptidões, exaurem suas forças na lógica da produção e, do outro lado, a regulação das populações são os polos em torno dos quais irá se instaurar e se desenvolver o "biopoder", o poder sobre a vida ${ }^{5}$.

A valorização do corpo estará em estreita conexão com a ordem burguesa, tornada hegemônica nesse momento histórico, não simplesmente, como enfatiza Foucault, pelo valor mercantil que o corpo assume em razão de sua força de trabalho, mas, sobretudo, pela consolidação política, histórica e cultural da referida hegemonia. Obras publicadas no final do século XVIII sobre higiene do corpo, longevidade, métodos para ter filhos saudáveis e evitar a mortalidade infantil, formas de melhorar a descendência da espécie humana, correlacionam o corpo e o sexo com um pensamento eugenista e de evidente racismo $0^{4,5}$.

Assim, instaura-se toda uma tecnologia do controle que irá possibilitar manter os corpos e a sexualidade sobre estreita vigilância, como forma de equacionar o tensionamento entre as classes sociais (burguesia e proletariado), através da delimitação das possibilidades de coabitação, proximidade $e$ contaminação (em razão das epidemias e doenças venéreas), de fluxo populacional e regulação demográfica. Logo, o corpo feminino - com o respaldo da medicina que destaca a fisiologia sexual própria das mulheres - será colocado a serviço da demografia, ao regular, de forma espontânea ou planejada, os nascimentos das crianças ${ }^{5}$.

Na primeira metade do século $X X$, o saber médico possibilitará, nos países desenvolvidos, a erradicação da mortalidade materna e infantil perinatal, quase que inteiramente, criando-se a partir daí um estreito vínculo entre medicina e procriação, cuja lógica se amplia com a exigência sempre crescente de salvar a díade mãe-criança dos riscos mortais que cercam o nascimento ${ }^{\circ}$.

A psicanalista Marie-Magdeleine Chatel destaca em seu ensaio Mal-estar na Procriaçãa ${ }^{6}$, que tal redução da mortalidade se fez acompanhar do surgimento da contracepção médica, que visava o controle do excesso de natalidade. Apesar de a prática contraceptiva não ser exatamente uma novidade, como atestam documentos da antiguidade egípcia, esteve proscrita e na clandestinidade durante muitos e muitos séculos de cristianismo, ganhando 
visibilidade neste preciso momento da história ${ }^{6}$.

Chatel ${ }^{6}$ salienta ainda que a contracepção médica forçou a disjunção entre o ato sexual e a procriação. Afirma: "a ideia de consequências, sob a forma de uma criança, foi se destacando cada vez mais do ato sexual" (p. 21). Contudo, a autora observa que o grande emprego dos contraceptivos e o alto grau de informações que circulavam na França naquele momento não foram suficientes para provocar uma diminuição significativa do número de abortamentos, levando-a a deduzir que as gestações ditas "indesejáveis" não podiam ser reduzidas à questão de ter ou não acesso aos métodos contraceptivos. Chatel ${ }^{6}$ identifica outros aspectos que vão mais além da decisão racional de ter ou não ter filhos.

Outras reviravoltas marcaram o século XX. Palco de intensos movimentos políticos, tais como a Revolução Socialista, em 1917; o emblemático Maio de 1968 na França, no qual estudantes universitários foram às ruas protestar contra o conservadorismo das instituições, encontrando apoio e adesão em massa da classe trabalhadora em quase toda a Europa; o Movimento de Contracultura dos hippies do hemisfério norte; o Movimento Feminista, entre outros, se constituíram como força contrária à dominação exercida pelo Estado, mas não apenas dele, como também a outras formas de controle mais sutis, capilarizadas em todo o tecido social.

A conjuntura de protestos, de reivindicações dos diversos segmentos da sociedade civil, de questionamentos à ordem instituída, criou as condições de possibilidade para a legalização do aborto na França, em 1975, que, embora rejeitada por alguns com $\circ$ argumento de que poderia se constituir como mais um método contraceptivo, provou justamente o contrário, ou seja, o número de abortamentos não aumentou, como também se testemunhou certo declínio e estabilização em determinado patamar ${ }^{6,7}$.

Neste mesmo período, o Brasil encontrava-se sob o regime da ditadura militar, mas, na contramão desse cenário político, estava em curso a Reforma Sanitária Brasileira simultaneamente e sintonizada com a luta para a redemocratização do país. É a Reforma Sanitária que cria as bases para o surgimento do Sistema Único de Saúde (SUS), instituído pela Constituição Brasileira de 1988, que reconhece a saúde como direito do cidadão e dever do Estado.

Jairnilson Paim e colaboradores ${ }^{8}$ destacam que uma característica fundamental da reforma sanitária no Brasil foi o fato dela ter sido conduzida pela sociedade civil, e não por governos, partidos políticos ou organizações internacionais. A proposta brasileira de reforma sanitária se iniciou nos anos setenta reunindo movimentos de base, sindicatos, intelectuais progressistas, membros associados aos partidos de esquerda e acabou por conceber um conceito de saúde que não a reduz à dimensão biológica, mas que reconhece sua dimensão social e política e a necessidade de discuti-la no espaço público?.

O Sistema Único de Saúde no Brasil está fundamentado nos princípios de universalidade, integralidade e equidade, que reconhecem a diversidade $e$ as pluralidades individuais e dos coletivos, tornando a participação social estratégica nesse modelo de saúde. Seu lastro advindo de uma reforma viva, articulada no seio da sociedade civil, possibilitou a criação de instâncias deliberativas, nas quais a participação popular torna-se fundamental para a formulação e controle das políticas e serviços de saúde, reduzindo as chances deste modelo de saúde funcionar como mero instrumento de dominação e controle do Estado sobre os indivíduos. Deste modo, a concepção do SUS garante os direitos e reconhece a autonomia de todos os cidadãos. Em 2003, a Política Nacional de Humanização (PNH) veio trazer reforços ao SUS, propondo tecnologias e dispositivos, a fim de efetivar este novo paradigma de saúde $e^{8,9}$.

Conceber a saúde de forma humanizada impõe reflexões sobre as formas de assistência às mulheres adultas e adolescentes em situações de abortamento, à medida que a temática do aborto gera grandes divergências e tensões que acabam por ameaçar, constantemente, os direitos conquistados pelas mulheres, a exemplo do Estatuto do Nascituro, Projeto de Lei $\mathrm{n}^{\circ}$ 478/07, que em 2007 colocou em questão a legitimidade e legalidade do aborto em circunstâncias já descriminalizadas pelo Código Penal Brasileiro de 1940, Art. $128^{10}$, que prevê a indução do Aborto Legal como meio de salvar a vida da gestante ou em caso de estupro. 
Em contrapartida, em 04 de abril de 2012 o Supremo Tribunal Federal (STF) julgou procedente a ação referente à Interrupção Seletiva da gravidez ou Aborto Seletivo, para os casos de gestação de fetos com anencefalia ${ }^{11}$. A discussão sobre o abortamento relacionada à incompatibilidade com a vida de fetos malformados foi reaberta no atual momento da história do país, em razão da epidemia do Zika Vírus estar correlacionada como - nascimento de bebês com microcefalia e outras malformações $^{12}$. Contudo, o tensionamento sobre questões relativas ao aborto é constante.

No presente cenário político há fortes pressões da bancada evangélica, formada por deputados líderes de comunidade religiosas que insistem em recolocar em pauta o Estatuto do Nascituro no âmbito do Congresso Nacional, cuja aprovação acarretaria um retrocesso sem precedentes para as mulheres no Brasil.

\section{A Política de Humanização em caso de abortamento}

No Marco Teórico $\mathrm{PNH}^{9}$ fica registrada a necessidade de mapear e de dar visibilidade às iniciativas e programas de humanização no SUS, promovendo o intercâmbio e a articulação destes programas como estratégia essencial para a construção da Rede de Humanização em Saúde (RHS)?.

Com essa delimitação, a Atenção Humanizada ao abortamento - Norma Técnica ${ }^{7}$, produzida pela Área Técnica de Saúde da Mulher, vai figurar como uma "publicação importante" no âmbito da $\mathrm{PNH}^{9}$.

A Norma Técnica' lançada pelo Ministério da Saúde em 2005, e revisada em 2011, considera que compreender a abrangência e o impacto do abortamento na saúde pública brasileira requer repensar soluções que exigem investimento em educação e informação, a fim de aprimorar a capacidade crítica dos cidadãos, retirando a discussão sobre o aborto da polaridade simplista ("ser contra" ou "a favor") permeada, quase sempre, de passionalidade e dissensão. A Norma' é proposta tendo em conta alguns princípios basilares, a saber: a democracia, a laicidade do Estado, a igualdade de gênero e a dignidade da pessoa humana, e afirma $\circ$ compromisso de resguardar os direitos reprodutivos e os direitos sexuais das mulheres.

Pesquisadores no campo da epidemiologia ${ }^{13,14}$ têm destacado que o enquadre restritivo da lei, no qual o aborto é considerado crime, dificulta o acesso aos dados que permitiriam precisar a magnitude do aborto provocado no Brasil; alguns pesquisadores ${ }^{13}$ não veem como garantir, com absoluta segurança, sigilo ou proteção às mulheres que participam das pesquisas ${ }^{13}$. Contudo, a Atenção humanizada ao abortamento - Norma Técnica ${ }^{1}$ traz as orientações necessárias para o exercício profissional no contexto hospitalar, cotejando a lei e o código de ética médica, de forma a garantir o cuidado sigiloso, técnico e humanizado'.

Em que pese a subnotificação dos casos abortamento, pode-se observar uma tendência ao declínio no número de óbitos. Todavia, constata-se uma curva inversamente proporcional quando os óbitos são correlacionados à idade'.

As pesquisadoras Menezes e Aquino no artigo Pesquisa sobre o aborto no Brasil: avanços e desafios para o campo da saúde coletiva ${ }^{14}$ destacam que as mortes por abortamento atingem as mulheres mais jovens, de contextos sociais desfavorecidos, residentes nas periferias das cidades, sendo as negras as mais vulneráveis, estando sob o risco três vezes superior de morrer por essa causa quando comparadas às brancas. Outro dado levantado pelas pesquisadoras nos estudos de investigação de óbitos maternos é a recorrência de suicídio de jovens grávidas ${ }^{14}$. Além disso, a morbidade ocasionada pelo abortamento pode ser constatada pelas complicações físicas que se seguem, tais como: hemorragias, infecções, perfurações de órgãos e infertilidade, acompanhadas de repercussões psicossociais complexas que exigem análises delicadas. No referido artigo ${ }^{14}$, as autoras apontam para a necessidade de investigação dos efeitos psíquicos do aborto, sobretudo nos países onde sua prática é crime, como no Brasil.

A Norma Técnica' define medidas protocolares a fim de reduzir as chances de complicações e danos irreversíveis. Entretanto, sua delimitação vai além da indicação dos procedimentos clínicos e técnicas adequadas para o esvaziamento uterino. Seu marco conceitual considera como elementos essenciais a atuação de uma equipe multiprofissional composta 
por médicos, enfermeiros, assistentes sociais e psicólogos, para oferecer acolhimento, escuta qualificada e orientação, a fim de atender às necessidades física e mental das mulheres adultas e adolescentes. A Norma ${ }^{1}$ destaca a importância de não julgar, o que implica, em última instância, a suspensão temporária dos próprios valores pessoais do profissional, de modo a poder escutar o outro em sua dimensão de alteridade, o que implica dizer que as concepções de mundo são distintas de um sujeito para outro.

Apesar de a Norma Técnica de Atenção Humanizada ao Abortamento ${ }^{1}$ assinalar uma tendência ao declínio de mortes no Brasil causadas por abortamentos, encontrou-se nos estados nordestinos a menor redução da taxa de mortalidade do país. No estudo de Martins-Melo e colaboradores ${ }^{15}$, no qual foram analisados dados do período de 1996 a 2012, observou-se que o estado da Bahia apresentou a maior razão de abortos inseguros por nascidos vivos (53,6 abortos em 100 nascidos vivos) e, em Salvador, levantamentos identificam que desde os anos noventa o abortamento permanece como a principal causa isolada de mortalidade materna, com adolescentes e jovens apresentando maiores riscos de morte ${ }^{1}$, o que torna fundamental debruçar-se sobre esta realidade.

\section{O atual cenário da assistência em situações de abortamento}

Estudos recentes ${ }^{13,14,16,17,18,22}$ sobre a problemática do abortamento no Brasil revelam o quanto a assistência prestada nos casos de aborto encontrase distante do que preconiza as normas brasileiras e instâncias internacionais.

Aquino e colaboradores, na pesquisa Qualidade da atenção ao aborto no Sistema Único de Saúde do Nordeste brasileiro: o que dizem as mulheres? ${ }^{16}$ realizada em três capitais (Salvador, Recife e São Luís), cotejando as normas do Ministério da Saúde e o grau de satisfação de 2.804 usuárias internadas em 19 hospitais por complicações do aborto, constataram que os critérios de "apoio social" e "direito à informação" tiveram uma avaliação muito ruim nas três cidades. A "qualidade técnica do cuidado" também foi mal avaliada, sendo a "continuidade do cuidado" - identificada através dos critérios: cuidados pós-alta, consulta de revisão, planejamento reprodutivo, acesso a métodos de contracepção e orientações sobre a gravidez - o aspecto que apresentou a situação mais crítica em todas as cidades ${ }^{16}$.

$\mathrm{Na}$ investigação Largada sozinha, mas tudo bem: paradoxos da experiência de mulheres na hospitalização por abortamento provocado em Salvador, Bahia, Brasil ${ }^{17}$ buscou-se a compreensão da experiência de mulheres internadas por abortamento provocado em três hospitais públicos de Salvador (BA). Segundo as autores, a vivência dessas mulheres desencadeou sentimentos negativos, pela dor física e emocional, amplificados pelo "não-cuidado" e atitudes de discriminação pelo aborto, por parte dos profissionais, indo, portanto, de encontro às atuais normas técnicas. $O$ paradoxo se instaura, para as pesquisadores, a partir do relato das usuárias, no qual sobressai a falta de informações e de apoio emocional, que demonstram a desassistência com privação de direitos, sendo que nem sempre tais aspectos foram percebidos pelas usuárias, que tenderam a avaliar positivamente a atenção recebida. Este trabalho sugere que, em razão dos poucos estudos sobre a atenção ao aborto, outras pesquisas devam ser empreendidas para abordar a satisfação das usuárias e qualidade dos serviços de saúde, consonantes com as diretrizes da Norma Técnica'.

Na pesquisa Percepções de profissionais de saúde sobre o cuidado ao abortamento em Salvador, BA, a autora Lívia Santos ${ }^{18}$ desenvolve um trabalho qualitativo, de enfoque antropológico, em três maternidades públicas de Salvador, no qual se constata que o conhecimento dos profissionais a respeito da Atenção Humanizada ao Abortamento: Norma Técnica ${ }^{1}$ é quase nulo; além disso, os entrevistados revelaram percepções estereotipadas sobre mulheres em situação de abortamento. Diz: "Os profissionais, sem distinção de categoria ocupacional, descrevem as usuárias que induziram o aborto como 'jovens', de 'classes baixas', 'pouco instruídas', 'carentes', 'anormais', ‘irresponsáveis' e de 'sexualidade desenfreada'."18.

A referida pesquisadora ${ }^{18}$ destaca que essas percepções não refletem os resultados de estudos populacionais mais amplos, a exemplo da investigação de âmbito federal 20 Anos de Pesquisas sobre Aborto no Brasil ${ }^{19}$, realizada em 
2009 com mulheres escolarizadas de 15 a 49 anos, na qual se constatou que 0 aborto foi crescente com a idade, em mulheres com relação estável, já tendo filhos, declarando professar algum credo religioso, sobretudo católico, e sendo usuárias de métodos anticoncepcionais. Esta contradição aponta para preconceitos voltados para adolescentes, cujos estereótipos as tornam invisíveis nos serviços de saúde quanto às suas reais necessidades e demandas específicas ${ }^{20,21}$.

Nessa perspectiva, Cecilia McCallum e colaboradores $^{22}$ vão buscar compreender aspectos importantes que se entrelaçam na relação entre mulheres/adolescentes usuárias dos serviços de atenção obstétrica e os profissionais de saúde. Na pesquisa $O$ dilema de uma prática: experiências de aborto em uma maternidade pública de Salvador, Bahia $^{22}$ as autoras destacam: "[...] a discriminação contra as mulheres que abortam não parte, apenas, de alguns profissionais, mas está integrada à estrutura, organização e 'cultura' institucionais, dificultando, ou mesmo impossibilitando, um atendimento 'humanizado'." (p.38) ${ }^{22}$.

As autoras ${ }^{22}$ reforçam a tese de que as atitudes dos profissionais não são isoladas, são engendradas e engendram o espaço simbólico da instituição; a cultura institucional cria processos, rotinas e fluxos de atendimentos, que não estão isentos de significação. Percebe-se toda uma gama de valores passados subliminarmente, a própria naturalização dos "hospitais-maternidade" como locais de assistência às mulheres em situação de abortamento revela - contexto irrefletido das práticas. Não causa estranheza nem se percebe, em geral, o caráter irônico que McCallum e colaboradoras ${ }^{22}$ destacam: "[...] é nesses lugares consagrados à maternidade que se inscreve o cuidado com aquelas que estão abortando." (p. 38) 22 .

Outro aspecto observado pelas pesquisadoras ${ }^{22}$ foi - fato de que as parturientes eram indistintamente chamadas de "mãe" (denominação muito recorrente em outros hospitais-maternidades); até mesmo uma mulher em situação de abortamento pode ser assim interpelada. $O$ nome próprio no contexto da hospitalização desaparece, sendo que o termo mais frequente utilizado pelos profissionais para referir-se às mulheres em processo de abortamento é "cureta". McCallum e colaboradoras ${ }^{22}$ sublinham:
"[...] nome do instrumento utilizado na curetagem, denominando-as por referência à tecnologia que são/serão submetidas" (p.45). Reduzidas assim ao instrumento ou a um termo genérico, essas usuárias são coisificadas, não sendo reconhecidas em sua humanidade 22 .

As pesquisadoras ${ }^{22}$ salientam que nesse cenário institucional negativo, as relações são pautadas pela desconfiança. As mulheres adultas e adolescentes temem ser discriminadas e maltratadas pelos profissionais de saúde e adiam sua ida ao hospital; quando admitidas na instituição, experimentam tensões e insegurança, além de captarem as mensagens simbólicas e subliminares. Ora, sendo - cuidado prioritário destinado às gestantes e parturientes, "às mães", as mulheres adultas e adolescentes em situação de abortamento ficarão relegadas ao papel desqualificado de "antimães"22. Aí reside o ponto de violência, destacado pelas autoras, silencioso e ao mesmo tempo gritante que questiona $\circ$ que está firmemente enraizado na estruturação deste cuidado ${ }^{22}$.

\section{CONSIDERAÇÕES FINAIS}

As estratégias e ações desenvolvidas pelo Ministério da Saúde para implementar uma atenção humanizada ao abortamento têm ainda um longo caminho a percorrer. Assim, a humanização da assistência não depende exclusivamente da promulgação de leis, decretos ou normativas e protocolos bem definidos. No campo relacional, o modo de pensar e agir dos profissionais é - elemento preponderante para a materialização das políticas públicas, para que não fiquem como meras abstrações de um modelo de saúde. $O$ posicionamento dos profissionais passa a ser de fundamental interesse: até que ponto estes se investem do biopoder ou, ao contrário, relativizam o dispositivo saber/poder, na direção de um modelo de saúde menos dessubjetivador e mais humano?

Humanizar a assistência nas situações de abortamento requer um profundo questionamento que desnaturalize formas de assistência já cristalizadas ao longo de um processo sócio-histórico; deve-se buscar, através do conhecimento técnico e, especialmente da reflexão e amadurecimento de questões éticas, políticas, jurídicas no marco dos direitos sexuais e reprodutivos - alcançar 
um novo paradigma de atenção à saúde, norteado pelos princípios que reafirmem a importância da dignidade da pessoa humana.

\section{REFERÊNCIAS}

1. Brasil. Ministério da Saúde. Secretaria de Atenção à Saúde. Departamento de Ações Programáticas Estratégicas. Atenção humanizada ao abortamento: norma técnica. $2^{a}$ ed. Brasília. 2011

2. Devereux G. A Study of Abortion in Primitive Societies: a typological, distributional, and dynamic analysis of the prevention of birth in 400 pre-industrial societies. New York: Julian Press; 1955

3. Boltanski L. As dimensões antropológicas do aborto. Rev. Bras. Ciênc. Pol. 2012 ;(7):205-245. doi: http://doi. org/10.1590/S0103-33522012000100010

4. Foucault M. O nascimento da biopolítica: curso dado no Collège de France (1978-1979). [Internet]. 2008. [citado 2016 abr. 28]. Disponível em: https:// gambiarre.files.wordpress.com/2011/01/foucaultnascimento-da-biopolc3adtica 1.pdf

5. Foucault $M$. Historia da sexualidade: A vontade de saber. $17^{a}$ ed. São Paulo: Graal LTDA; 2006

6. Chatel MM. Mal-estar na procriação - as mulheres e a medicina da reprodução. Rio de Janeiro: Campo Matêmico; 1995

7. Dehlinger $M$. Trois chiffres pour comprendre l'IVG en France, 40 ans. [Internet]. 2015. [citado 2016 fev. 21]. Disponível em: http://www.francetvinfo.fr/societe/ivg/ trois-chiffres-pour-comprendre-l-ivg-en-france-40-ansapres-sa-depenalisation_797623.html

8. Paim J, Travassos C, Almeida C, Bahia L, Maclnko J. The Brazilian health system: History, advances, and challenges. The Lancet. 2011 ;377(9779):1778-1797. doi: http://doi.org/10.1016/S0140-6736(1 1)600548

9. Brasil. Ministério da Saúde, Secretaria de Atenção à Saúde, Núcleo Técnico da Política Nacional de Humanização. HumanizaSUS: Documento base para gestores e trabalhadores do SUS. $4^{a}$ ed. Brasília. DF. 2008
10. Brasil. Tribunal de Justiça do Estado do Rio Grande do Sul. Código Penal [1940] e Código de Processo Penal [1941]. 6 ${ }^{a}$ ed. Porto Alegre. 2013

11. Instituto de Bioética, Direitos Humanos e Gênero. Anencefalia: o pensamento brasileiro em sua pluralidade. Instituto de Bioética, Direitos Humanos e Gênero [Internet]. 2004 [citado 2016 abr. 28]. Disponível em: http://www.anis.org.br/ biblioteca/2015-11/anencefalia_pensamento_ brasileiro_pluralidadepdf.pdf

12. Dias BC. Ação para aborto em casos de microcefalia será apresentada ao STF. Associação Brasileira de Saúde Coletiva. [Internet]. 2016 [citado 2016 abr. 28]. Disponível em: https://www.abrasco. org.br/site/2016/01/bioetica-aborto-em-casos-demicrocefalia/

13. Diniz D, Medeiros M. Aborto no Brasil: uma pesquisa domiciliar com técnica de urna. Ciência \& Saúde Coletiva. 2010;15:959-966. doi: http://doi. org/10.1590/S1413-81232010000700002

14. Menezes G, Aquino EML. Pesquisa sobre o aborto no Brasil: avanços e desafios para o campo da saúde coletiva. Cad. Saúde Pública. 2009;(25 suppl.2):s193-s204. doi: http://dx.doi.org/10.1590/ so102-311X2009001400002

15. Martins-Melo FR, Lima MS, Alencar CH, Jr. Ramos NA, Carvalho FH, Machado MMT, et al. Tendência temporal e distribuição espacial do aborto inseguro no Brasil, 1996-2012. Rev. Saúde Pública. 2014 ;48(3):508-520. doi: http://dx.doi.org/10.1590/ s0034-8910.2014048004878

16. Aquino EML, Menezes G, Araújo TVB, Alves MR, Alves SV, Almeida MCC et al. Qualidade da atenção ao aborto no Sistema Único de Saúde do Nordeste brasileiro: o que dizem as mulheres?. Rev. Ciência \& Saúde Coletiva. 2012;17(7):1765-1775. doi: http:// dx.doi.org/10.1590/S1413-81232012000700015

17. Carneiro MF, Iriart JAB, Menezes GMS. "Largada sozinha, mas tudo bem": paradoxos da experiência de mulheres na hospitalização por abortamento provocado em Salvador, Bahia. Interface. 2013;17(45):405-18

18. Santos LLN. Percepções de profissionais de saúde sobre o cuidado ao abortamento em Salvador, BA [Dissertação]. Salvador: Instituto de Saúde Coletiva, Universidade Federal da Bahia; 2014

19. Brasil. Ministério da Saúde, Secretaria de Ciência, 
Tecnologia e Insumos Estratégicos, Departamento de Ciência e Tecnologia. 20 anos de pesquisas sobre aborto no Brasil. Brasília. DF; 2009

20. Brasil. Ministério da Saúde, Secretaria de Atenção à Saúde, Departamento de Ações Programáticas Estratégicas. Política nacional de atenção integral à saúde da mulher: princípios e diretrizes. Brasília. DF; 2009

21. Brasil. Ministério da Saúde, Secretaria de Atenção à Saúde, Departamento de Ações Programáticas Estratégicas. Marco teórico e referencial: saúde sexual e saúde reprodutiva de adolescentes e jovens. Brasília. DF; 2007

22. McCallum C, Menezes G, Reis AP. O dilema de uma prática: experiências de aborto em uma maternidade pública de Salvador, Bahia. História, Ciências, Saúde. 2016 ;23(1):37-56. doi: http://dx.doi.org/10.1590/

s0104-59702016000100004 